\title{
A prospective study of the incidence and outcomes of eclampsia in a tertiary care hospital and teaching institute in India
}

\author{
Garima Gandhi ${ }^{1}$, Kavita Chandnani ${ }^{2 *}$
}

\begin{abstract}
${ }^{1}$ Department of Obstetrics and Gynecology, Medical College Baroda, Vadodara, Gujarat, India
${ }^{2}$ Department of Obstetrics and Gynecology, SBKS Medical Institute and Research Centre, Piparia, Vadodara, Gujarat, India
\end{abstract}

Received: 10 May 2019

Accepted: 05 June 2019

\author{
*Correspondence: \\ Dr. Kavita Chandnani, \\ E-mail: kavyawch@rediffmail.com
}

Copyright: () the author(s), publisher and licensee Medip Academy. This is an open-access article distributed under the terms of the Creative Commons Attribution Non-Commercial License, which permits unrestricted non-commercial use, distribution, and reproduction in any medium, provided the original work is properly cited.

\begin{abstract}
Background: Eclampsia is a common cause of maternal and foetal morbidity and mortality in India and the rest of the world accounting for nearly $10 \%$ of all maternal deaths. However, there is a relative scarcity of outcome data for patients with eclampsia in India. Our goal was to estimate the incidence of eclampsia, the maternal and foetal outcomes of patients presenting with eclampsia, and predictors of clinical outcomes in these patients. Objective of this study was to estimate the incidence of eclampsia in patients who delivered at a single tertiary care institution over a 2year period and to study the maternal and perinatal outcomes in those patients.

Methods: Prospective cohort study conducted from September 2008 to August 2010 on all patients with eclampsia admitted during the study period at Lok Nayak Hospital, New Delhi, India.

Results: The incidence of eclampsia among total deliveries was $0.45 \%$. About $97 \%$ of these patients received parenteral magnesium sulphate as the primary anticonvulsant therapy. Caesarean section was performed in $22.7 \%$ and majorities were done for foetal distress. Maternal complications were encountered among $17 \%$ of patients. There were 2 maternal deaths $(2.3 \%), 13$ stillbirths $(14.1 \%)$ and 7 early neonatal deaths $(7.9 \%)$.

Conclusions: The incidence of eclampsia among all deliveries over a 2-year period at a tertiary care centre in India was $0.45 \%$. Parenteral magnesium sulphate was effective in the vast majority of these patients in controlling the seizures. Further studies to evaluate whether early registration for antepartum care improves maternal and foetal outcomes in patients with eclampsia are warranted.
\end{abstract}

Keywords: Eclampsia, Maternal outcome, Magnesium sulphate, Perinatal outcome

\section{INTRODUCTION}

Eclampsia is a common cause of maternal and foetal morbidity and mortality in India and the rest of the world accounting for nearly $10 \%$ of all maternal deaths worldwide. ${ }^{1}$ Most cases occur in third trimester of pregnancy or within 48 hours following delivery, but cases of late-onset eclampsia have been described even up to 2 to 3 weeks postpartum. In developed countries, the incidence of eclampsia has been reported to be 1.5 to 10 cases per 10,000 deliveries. $^{2-8}$ On the other hand, the incidence reported from developing countries is 6 to 157 cases per 10,000 deliveries (Table 3). ${ }^{9-17}$ In India, incidence of eclampsia is noted to be 150 per 10,000 deliveries $(1.5 \%)$ while the maternal mortality in these patients is 2.2 to $9 \% .^{18}$ Perinatal mortality rate in eclampsia cases in India is as high as 24.5 to $48 \% .^{18}$ But in developed countries the corresponding mortality rates 
are much less probably due to early diagnosis and aggressive management. In U.K, incidence of Eclampsia was reported to be $4.9 / 10,000$ and out of these $1.8 \%$ women died. ${ }^{2}$

It has been observed that the incidence is lower in antenatally booked cases compared to unbooked cases. In India, more than half the cases of eclampsia occur antepartum and around $20 \%$ cases occur postpartum, though in developed countries intrapartum and postpartum eclampsia is commoner than antepartum eclampsia. ${ }^{18}$ In U.K, $44 \%$ of cases occurred postpartum, more than a third $(38 \%)$ antepartum, and the remainder (18\%) intrapartum. ${ }^{2}$ In a systematic review done using data from 26 countries, out of 18,488 eclamptic women, the proportion of antepartum, intrapartum and postpartum eclampsia was $59 \%, 20 \%$ and $21 \%$, respectively. ${ }^{19}$ Most of the postpartum seizures occur within 1 week of delivery. ${ }^{20-24}$

For management of convulsions in eclampsia, magnesium sulphate appears to be the ideal anticonvulsant. ${ }^{25-27}$ A landmark study, "MAGPIE trial", done worldwide, demonstrated that administration of magnesium sulphate to women with preeclampsia reduces the risk of an eclamptic seizure by $58 \% .^{28}$ Randomized trials have demonstrated that magnesium sulphate reduces the rate of recurrent seizures by one half to two thirds and the rate of maternal death by one third. ${ }^{29}$

Most of the studies related to eclampsia have been done in developed countries whereas eclampsia is much more common in developing countries. Also, most of the existing studies are retrospective in nature. The incidence of eclampsia in India has been mostly calculated based on personal communication from various institutions and the true incidence remains unknown. Furthermore, various anticonvulsant therapies are used for management of eclampsia especially in the community hospitals, despite recent studies showing many of those therapies not to be so useful. The influence of those various regimens in affecting the morbidity and mortality of mother and foetus need further evaluation.

In order to provide better care, it's paramount to accurately estimate the incidence and subsequent outcomes of these patients. Our study was done with the objective of estimating the incidence of eclampsia in patients who delivered at the institution over 2-year period and to study the maternal and perinatal outcomes in the above patients.

\section{METHODS}

This was a prospective cohort study conducted on all patients with eclampsia admitted over a 2-year period from September 2008 to August 2010 at Lok Nayak Hospital and associated Maulana Azad Medical College, New Delhi, India.

\section{Inclusion criteria}

- All patients with eclampsia, as per currently accepted criteria, whether antepartum, intrapartum or postpartum, admitted during the study period.

\section{Exclusion criteria}

- Patients with seizures due to causes other than eclampsia, as diagnosed based on previous history of epilepsy, absence of hypertension, occurrence of convulsions before 20 weeks of gestation in absence of molar pregnancy or after 3 weeks postpartum were excluded from the study.

All the 89 patients diagnosed with eclampsia during the study period were managed as per standard management protocols of the hospital which included general supportive care, anticonvulsant therapy, antihypertensive treatment, blood component transfusion as per requirement, and induction of labour for all the antepartum patients irrespective of the gestational age. All women were followed up until discharge from hospital after delivery.

\section{Outcome measures}

- Incidence of eclampsia

- Maternal mortality

- Perinatal mortality and morbidity

- Maternal complications

- $\quad$ Need for ICU care

\section{Statistical analysis}

A study pro forma was designed to record demographic information, history including obstetric history, convulsions history, treatment history as well as examination findings, and maternal and foetal outcomes. Data were analysed once all the relevant information was collected on all patients during the study period. The recorded maternal and foetal outcomes are presented here as frequencies and percentages.

\section{RESULTS}

A total of 89 patients with eclampsia were identified from a total of 19,654 patients who delivered at the institution during the study period, corresponding to a cumulative incidence of $0.45 \%$. Out of these, 48 (54\%) were patients referred from other institutions.

As illustrated in Figure 1, the majority of patients were aged 20 to 29 years $(70 \%)$. Among eclamptic patients, only $11 \%$ were teenage pregnancies while nearly $20 \%$ were greater than or equal to 30 years of age.

As per the results of our study, eclampsia was primarily a disease of primigravidas as depicted in Figure 2. Only 
$12 \%$ of women had greater than or equal to two previous deliveries.

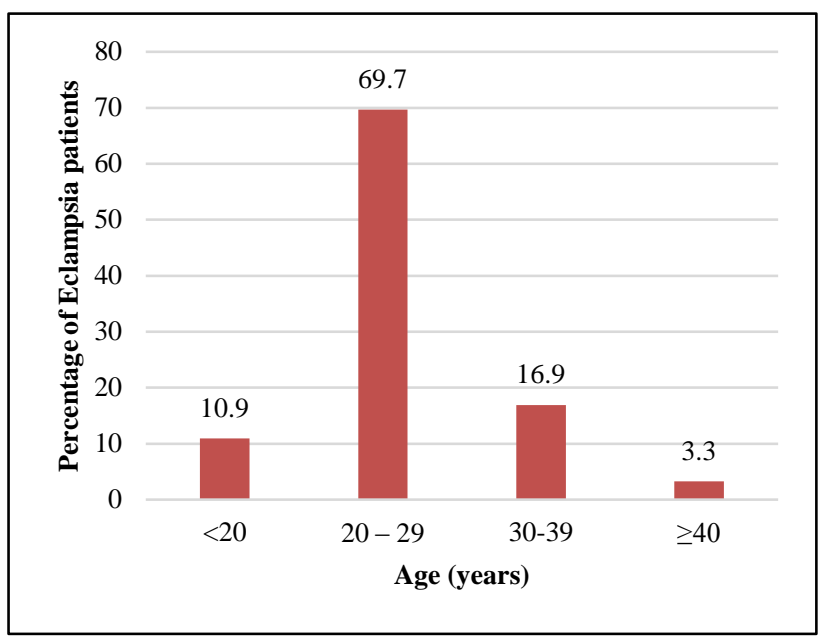

Figure 1: Age distribution of patients with eclampsia.

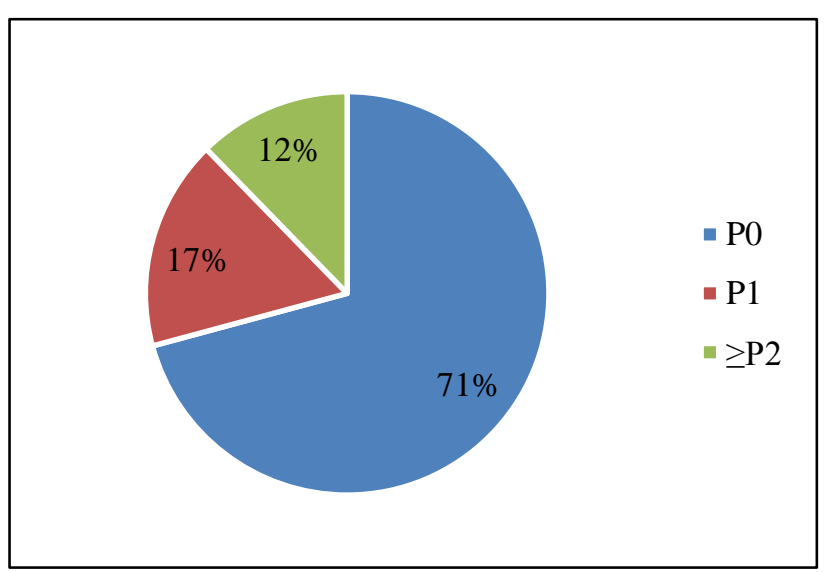

Figure 2: Eclampsia in relation to parity.

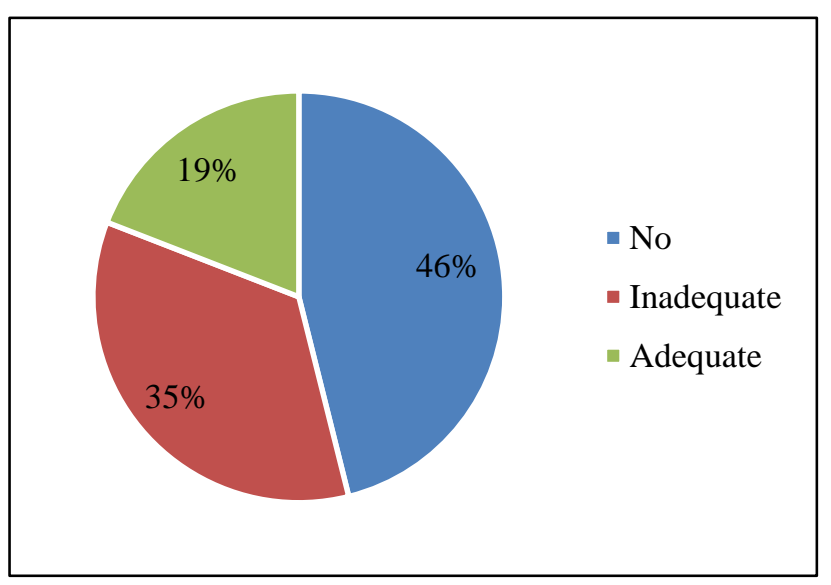

Figure 3: Antenatal care.

Figure 3 illustrates that four-fifths of the eclamptic patients had received no or minimal prior antenatal care while one-fifth of the eclamptic patients had convulsions despite adequate antenatal care.
Majority of the eclamptic patients at our institute were antepartum at the time of presentation (78\%) as shown in Figure 4. Only $10 \%$ of patients had their first episode of convulsion in the postpartum period.

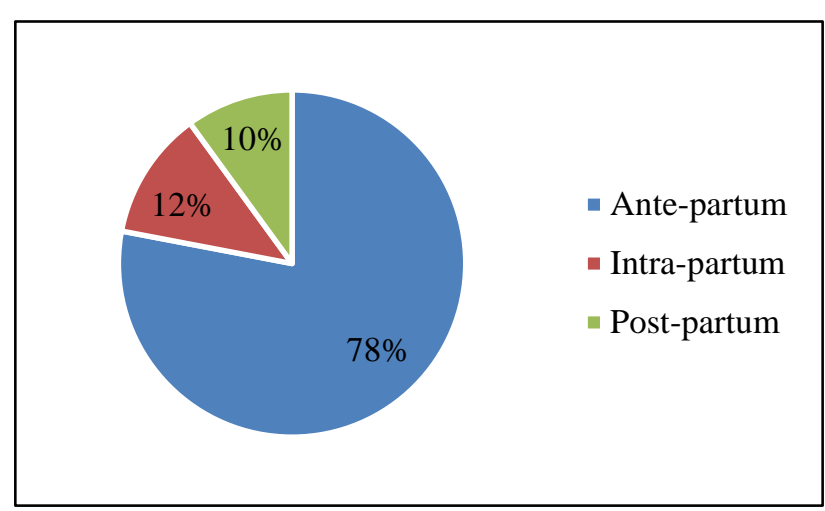

Figure 4: Type of eclampsia.

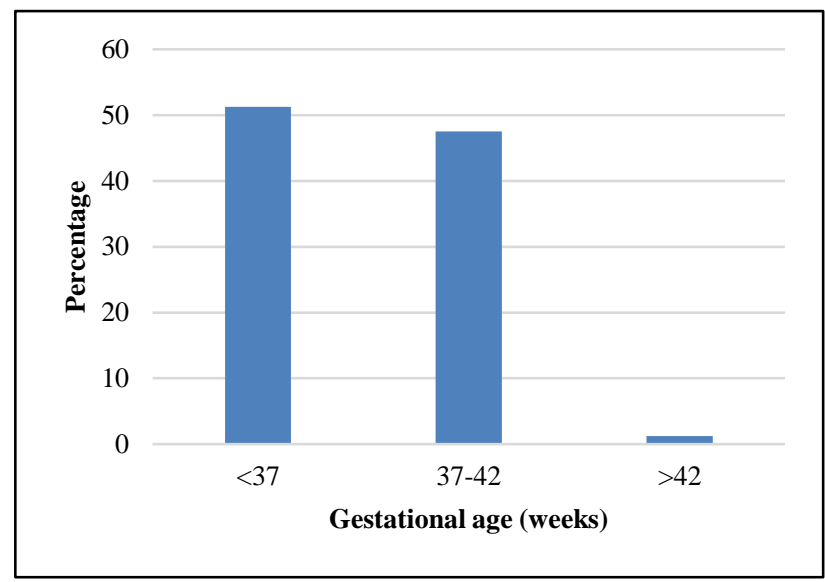

Figure 5: Duration of gestation at the onset of convulsions (antepartum and intrapartum patients).

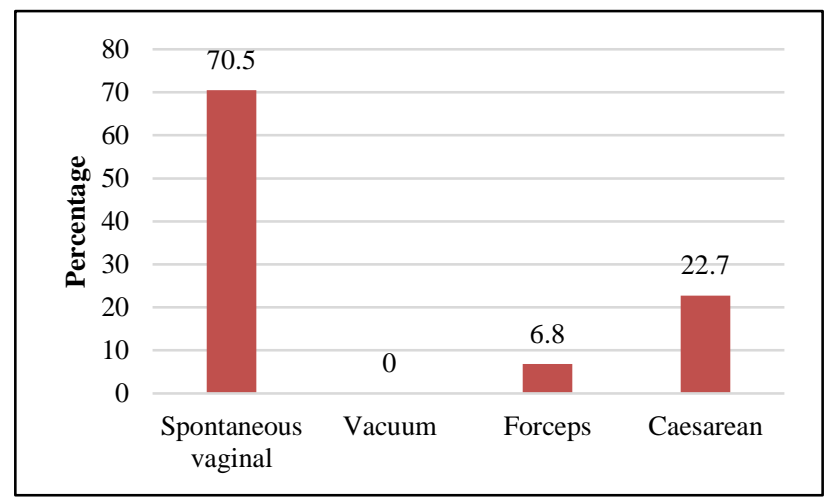

Figure 6: Mode of delivery.

Also, most of the patients belonged to low socioeconomic status and had singleton pregnancies (95.5\%). Majority of them $(85 \%)$ started having convulsions at home but $15 \%$ had first episode of convulsion while already admitted in the hospital. Only $17 \%$ of patients who convulsed first time outside the hospital, presented to hospital within 2 
hours of first convulsion. Nearly $16 \%$ of convulsing patients were brought to the hospital 10 hours after the onset of the first episode of convulsions. About $97 \%$ of eclamptic patients received parenteral magnesium sulphate as the primary anticonvulsant therapy and $90 \%$ of those did not require any additional or alternative anticonvulsant therapy. Nearly $50 \%$ of these patients had blood pressure greater than or equal to $160 / 110$ at the time of admission while albuminuria $(>/=1+$ on urine dipstick testing) was present in $81 \%$ of them.

Of all the patients with antepartum or intrapartum eclampsia, more than half $(51.25 \%)$ were preterm while $47.5 \%$ had term pregnancies. Only a single patient had post-term pregnancy with gestational age of 42 weeks and 3 days (Figure 5).

As seen in Figure 6, caesarean section was performed on $22.7 \%$ patients and the majority were done for foetal distress; $6.8 \%$ of patients required forceps assisted vaginal delivery. Majority of the eclamptic patients $(70.5 \%)$ at our institute during the study period delivered vaginally. The following figure presents the percentages of different modes of delivery among 88 eclamptic patients who delivered during the study period, while 1 patient died undelivered.

Table 1: Maternal outcomes.

\begin{tabular}{|lll|}
\hline Outcome & N & $\%$ \\
\hline Caesarean section & 20 & 22.7 \\
\hline Serious maternal complications & 15 & 16.9 \\
\hline ICU admission & 7 & 7.9 \\
\hline Maternal deaths & 2 & 2.3 \\
\hline
\end{tabular}

Table 2: Perinatal outcomes.

\begin{tabular}{|lll|}
\hline Outcome & N & $\%$ \\
\hline Live birth & 79 & 85.9 \\
\hline Still birth & 13 & 14.1 \\
\hline Birth weight & & \\
\hline$<2.5 \mathrm{~kg}$ & 67 & 72.8 \\
\hline$\geq 2.5 \mathrm{~kg}$ & 25 & 27.2 \\
\hline Maturity & & \\
\hline Pre term & 49 & 53.3 \\
\hline Term & 42 & 45.6 \\
\hline Post term & 1 & 1.1 \\
\hline
\end{tabular}

As depicted in Table 1, 16.9\% of the patients met with serious maternal complications while $7.9 \%$ required intensive care unit admission. Complications included postpartum haemorrhage, hypertensive encephalopathy, accelerated hypertension, HELLP syndrome (Haemolysis, elevated liver enzymes, low platelet count), placental abruption, cerebral oedema, cerebrovascular haemorrhage, DIC (disseminated intravascular coagulation), acute renal failure and puerperal sepsis. Forty-five women were anaemic and 3 had severe anaemia, 8 had thrombocytopenia, 13 had deranged KFT (kidney function test), and 44 had elevated liver enzymes while 2 had deranged INR (international normalized ratio). Hypertensive retinal changes were noted in 7 of 53 cases where fundoscopy was done. Maternal injuries (tongue-bite) occurred in 18 women. There were 2 maternal deaths $(2.3 \%)$, out of which one patient died before delivery. Eclampsia contributed to $4.7 \%$ of 43 total maternal mortalities during the study period. Maternal case fatality rate was 2.3 percent. Out of the two patients who died, one had cerebrovascular haemorrhage and the other had DIC with acute renal failure. Average duration of hospital stay was 10 days. Only $20 \%$ of patients had a hospital stay of over 2 weeks.

There were 4 twin deliveries and hence 92 neonates were born of 88 deliveries. As illustrated in Table 2, there were 79 live births $(85.9 \%)$. Of all the neonates, $49(53.3 \%)$ were preterm. Nearly $73 \%$ of the babies born to the patients with eclampsia were low birth weight (less than $2.5 \mathrm{~kg}$ ). Approximately $20 \%$ among live born babies had an APGAR score of less than 5 at 1 minute after birth and $10 \%$ of live born babies had APGAR score of less than 5 at 5 minutes after birth. There were 13 stillbirths (14.1\%) and 7 early neonatal deaths accounting for a perinatal mortality rate of 253 per 1000 live births, still-birth rate of 141 per 1000 births and early neonatal mortality rate of 88.6 per 1000 live births. The major causes of perinatal mortality were prematurity and birth asphyxia.

\section{DISCUSSION}

In this study of 19,645 deliveries, we found a cumulative incidence of $0.45 \%$ for eclampsia over a 2 -year period. Despite being a referral institute and tertiary care centre, the incidence of eclampsia at our institute was less as compared to the incidence reported from other studies in developing countries (Table 3) but more than the incidence reported from developed countries. ${ }^{2-18}$

In our study, the majority of eclamptic patients were primigravidas, belonged to low socioeconomic status, had received minimal or no antenatal care and were antepartum at presentation. Also, there was a delay in seeking tertiary level medical care after the onset of convulsions. Further, a significant proportion of patients underwent caesarean section $(22.7 \%)$ which was higher than the average caesarean section rate in our institute (17\%) but still much lower than another Indian study by Jain et al who reported a caesarean section rate as high as $68 \%$ among all 124 eclamptic patients. ${ }^{12}$ Their higher caesarean section was primarily attributed to poor Bishop's score in their patients.

Eclampsia being a very important cause of maternal morbidity and mortality, various studies have been done worldwide. A large prospective study was done in United Kingdom by Douglas and Redman which included all the eclampsia patients in United Kingdom in 1992. ${ }^{2}$ There were 383 confirmed cases of eclampsia providing a national incidence of $4.9 / 10,000$ maternities. It was 
concluded that eclampsia is associated with high maternal morbidity and mortality. It may present unheralded by warning signs. Preterm and antenatal eclampsia was deemed to be particularly severe. Seventy percent of eclampsia cases occurred despite antenatal care and $1.8 \%$ women died. The rates of stillbirths and neonatal deaths were 22.2/1000 and 34.1/1000 respectively.

Table 3: Comparison of incidence of eclampsia reported by various researchers from developing countries.

\begin{tabular}{|lll|}
\hline Author & Place of study & $\begin{array}{l}\text { Incidence of } \\
\text { eclampsia }\end{array}$ \\
\hline Kurude et al & Mumbai, India & $1.4 \%$ \\
\hline Raji et al & $\begin{array}{l}\text { Tamil Nadu, } \\
\text { India }\end{array}$ & $0.83 \%$ \\
\hline Gawandi et al & Solapur, India & $1.09 \%$ \\
\hline Jain et al & $\begin{array}{l}\text { Madhya } \\
\text { Pradesh, India }\end{array}$ & $1.3 \%$ \\
\hline Doley et al & Assam, India & $0.71 \%$ \\
\hline Maji et al & West Bengal, India & $1.84 \%$ \\
\hline Eke et al & Nigeria & $1.57 \%$ \\
\hline Miguil et al & $\begin{array}{l}\text { Casablanca, } \\
\text { Morocco }\end{array}$ & $0.91 \%$ \\
\hline Nobis et al & India & $1.5 \%$ \\
\hline $\begin{array}{l}\text { Gandhi et al } \\
\text { (this study) }\end{array}$ & New Delhi, India & $0.45 \%$ \\
\hline
\end{tabular}

A 5 year retrospective study from 1994 to 1999 was done among 216 eclampsia cases in two teaching hospitals of Addis Adaba in Ethiopia with the objective of measuring the magnitude of eclampsia and its maternal and perinatal outcome. ${ }^{30}$ Incidence of eclampsia was found to be $7.1 / 1000$ deliveries. Sixty two percent of patients developed eclampsia in antepartum period while $22.7 \%$ were intrapartum and another $15.7 \%$ were postpartum. Caesarean Section rate among eclampsia patients $(45.8 \%)$ was much higher than non eclamptic patients $(16.6 \%)$. The multiple pregnancy rate was $5.7 \%$ which was significantly higher than the rate among the general population $(1.5 \%)$ at the same time. Case fatality rate was 13 percent. Perinatal mortality rate was 312.2/1000 deliveries.

A retrospective study conducted in Nigeria included all eclampsia patients admitted to the University of Benin Teaching hospital over 8 years from 1995 to 2002. Incidence of eclampsia was found to be $1.32 \%$. Significantly higher incidence of eclampsia was observed in nulliparous and unbooked mothers. ${ }^{31}$ About $86 \%$ of patients had antepartum eclampsia. Perinatal mortality rate was 214/1000 and was mainly attributed to prematurity and birth asphyxia. Maternal case fatality rate was $10.7 \%$ and maternal mortality ratio from eclampsia was 140/100,000. The clinical causes of deaths were cardiopulmonary failure, acute renal failure, haemolysis, elevated liver enzymes, low platelet count (HELLP syndrome) and cerebrovascular accident.
A study similar to ours was done by Kurude et al, at Grant Medical College, Mumbai, India. ${ }^{9}$ The incidence of eclampsia was found to be $1.4 \%$, which is almost thrice that of our study. In their study, $45 \%$ of patients were unbooked and $71 \%$ were primigravidas like in our study. As in our study, three fourths of the patients had antepartum eclampsia, but their caesarean section rate $(44 \%)$ was almost double that of our study.

The case fatality rate in our study was $2.3 \%$ which was less than one half of that $(6.16 \%)$ reported by Raji et al in a prospective study conducted at Government Thanjavur Medical College hospital, Tamil Nadu, India. ${ }^{10}$ Though this study had similar proportion of young patients (aged 20 to 25 years), primigravidas and antepartum cases as in our study, their caesarean section rate $(61.65 \%)$ was much higher than our study $(22.7 \%)$. Majority of their caesarean sections were done for poor Bishop's score $(56.67 \%)$, while the commonest indication for caesarean section in our study was foetal distress. Despite higher caesarean rate, the stillbirth rate $(24.3 \%)$ and neonatal death rate $(26.36 \%)$ was higher in their study compared to ours.

Gawandi et al, conducted a retrospective study over two years at Government Medical College, Solapur, India and found the incidence of eclampsia to be $1.09 \% .^{11}$ Their case fatality rate from eclampsia $(2.74 \%)$ was similar to our study $(2.3 \%)$. Also, as in our study, one of their patients died undelivered. The caesarean section rate in this study $(45.85 \%)$ was double of ours despite having similar proportion of primigravidas (75.27\%) and unbooked patients.

In a study, conducted on 50 eclamptic patients at the Federal Medical Centre, Azare, Nigeria, the patients were randomized for delivery either by caesarean section or induction of labour with misoprostol. ${ }^{32}$ The duration of admission was longer in the caesarean section group (mean of 10.1 days) compared to the misoprostol group (mean of 6.08 days). Maternal complications were higher in the caesarean section group while maternal mortality in the two groups was similar.

A trial was conducted among 200 rural Indian women at gestational age greater than or equal to 34 weeks with eclampsia, where patients were randomly allocated to either caesarean delivery or induction after initial stabilization. ${ }^{33}$ Results showed that planned Caesarean delivery did not significantly reduce the rate of adverse maternal or foetal outcomes. Also, almost three-quarters of women in the planned vaginal delivery group succeeded in delivering vaginally. Their vaginal delivery rate was close to the same in our study.

In most of the studies reported from developing countries, as also in our study, majority of the eclamptic patients were antepartum at the time of first episode of convulsions; while in studies reported from developed countries, the majority of eclamptic patients were either 
intrapartum or postpartum; probably reflecting the difference in antenatal care. ${ }^{2-18}$ Also, the incidence of eclampsia is much less in developed countries compared to developing countries.

For prevention of recurrent convulsions in patients diagnosed with eclampsia, it has been shown in systematic reviews that magnesium sulphate is safer and more effective than phenytoin, diazepam or lytic cocktail. ${ }^{34-36}$ In our study, we found that magnesium sulphate was effective in $90 \%$ of cases for the same, thus strengthening the previous recommendation about this treatment.

There are various limitations and strengths of our study. The major limitation of our study is the possibility of selection bias- majority of the patients that were studied for the incidence of eclampsia are those that were referred to our tertiary-care institution from elsewhere. Furthermore, vast majority of all patients in our study belonged to the lower socioeconomic strata, limiting generalisability of our findings. The major strength of our study is that it is a prospective study with a large sample size. During the 2-year study period, all the patients admitted to the institute and diagnosed to have eclampsia were individually and closely followed by a single observer (GG) from the time of admission to the time of discharge. As such, the risk of missed data is greatly reduced as compared to some of the previously retrospective studies that were using information from case records.

\section{CONCLUSION}

The overall incidence of eclampsia appears to be quite low at our tertiary-care institution. Parenteral magnesium sulphate was effective in the vast majority of these patients in controlling the seizures. However, despite that, a significant percentage of patients required operative intervention for delivery for foetal distress. Further studies to evaluate whether early registration for antepartum care improves maternal and foetal outcomes in those ultimately diagnosed with eclampsia are warranted.

Funding: No funding sources

Conflict of interest: None declared

Ethical approval: Not required

\section{REFERENCES}

1. Duley L. Maternal mortality associated with hypertensive disorder of pregnancy in Africa, Asia, Latin America and Caribbean. Br J Obstet Gynecol. 1992;99(7):547-53.

2. Douglas KA, Redman CW. Eclampsia in the United Kingdom. BMJ. 1994;309:1395.

3. Tuffnell DJ, Jankowicz D, Lindow SW, Lyons G, Mason GC, Russell IF, et al. Outcomes of severe pre- eclampsia/eclampsia in Yorkshire 1999/2003. BJOG. 2005; $112: 875$.

4. Liu S, Joseph KS, Liston RM, Bartholomew S, Walker M, León JA, et al. Incidence, risk factors, and associated complications of eclampsia. Obstet Gynecol. 2011;118:987.

5. Tan KH, Kwek K, Yeo GS. Epidemiology of preeclampsia and eclampsia at the KK Women's and Children's Hospital, Singapore. Singapore Med J. 2006;47:48.

6. Fong A, Chau CT, Pan D, Ogunyemi DA. Clinical morbidities, trends, and demographics of eclampsia: a population-based study. Am J Obstet Gynecol. 2013;209:229.e1.

7. Jaatinen N, Ekholm E. Eclampsia in Finland; 2006 to 2010. Acta Obstet Gynecol Scand. 2016;95:787.

8. Schaap TP, van den Akker T, Zwart JJ, van Roosmalen J, Bloemenkamp KWM. A national surveillance approach to monitor incidence of eclampsia: The Netherlands Obstetric Surveillance System. Acta Obstet Gynecol Scand. 2019;98:342.

9. Kurude VN, Kokate PH, Saha D, Jha EK. Study of maternal and perinatal outcome in eclampsia. PIJR. 2017;6(4):63-5.

10. Raji C, Poovathi M, Nithya D. Prospective study of fetomaternal outcome in eclampsia in a tertiary care hospital. Int J Reprod Contracept Obstet Gynecol. 2016;5:4329-34.

11. Gawandi P, Shinde MA, Jadhav CA. Clinical study of eclampsia patients at DR.V M. Government medical college Solapur, India. IOSR-JDMS, 2014;13(7):10-6.

12. Jain R, Bindal J. Maternal and perinatal outcomes in eclampsia: a retrospective analysis in a referral hospital. Int J Reprod Contracept Obstet Gynecol 2017;6:2806-11.

13. Doley R, Pegu B, Hazarika D. Clinical study of eclampsia in a tertiary care hospital. Indian $\mathbf{J}$ Sci Technol. 2016;9(29):1-5.

14. Maji B, Samanta S, Banerjee S, Hassan MT, Saharay S, Sarkar D. Clinico-epidemiological profile of eclampsia patients admitted in an urban tertiary care hospital of West Bengal: a record based study. Int $\mathbf{J}$ Community Med Public Health. 2018;5(6):2416-20.

15. Geographic variation in the incidence of hypertension in pregnancy. World Health Organization International Collaborative Study of Hypertensive Disorders of Pregnancy. Am J Obstet Gynecol. 1988;158:80.

16. Eke AC, Ezebialu IU, Okafor C. Presentation and outcome of eclampsia at a tertiary center in South East Nigeria--a 6-year review. Hypertens Pregnancy. 2011;30:125.

17. Miguil M, Chekairi A. Eclampsia, study of 342 cases. Hypertens Pregnancy. 2008;27:103.

18. Nobis PN, Hajong A. Eclampsia in India through the decades. J Obstet Gynecol India. 2016;66(Suppl 1):172-6.

19. Berhan Y, Berhan A. Should magnesium sulfate be administered to women with mild pre-eclampsia? A 
systematic review of published reports on eclampsia. J Obstet Gynaecol Res. 2015;41(6):831.

20. Dahmus MA, Barton JR, Sibai BM. Cerebral imaging in eclampsia: magnetic resonance imaging versus computed tomography. Am J Obstet Gynecol. 1992;167:935.

21. Van Weert JM, Hajenius PJ, Richard E, Wolf H, Bleker OP. Late postpartum eclampsia. Ned Tijdschr Geneeskd. 2007; 151:414.

22. Mattar F, Sibai BM. Eclampsia. VIII. Risk factors for maternal morbidity. Am J Obstet Gynecol. 2000;182:307.

23. Singhal AB, Kimberly WT, Schaefer PW, HedleyWhyte ET. Case records of the Massachusetts General Hospital. Case 8-2009. A 36-year-old woman with headache, hypertension, and seizure 2 weeks postpartum. N Engl J Med. 2009;360:1126.

24. Al-Safi Z, Imudia AN, Filetti LC, Hobson DT, Bahado-Singh RO, Awonuga AO. Delayed postpartum preeclampsia and eclampsia: demographics,clinical course, and complications. Obstet Gynecol. 2011;118:1102.

25. Sibai BM. Magnesium Sulphate is the ideal anticonvulsant in preeclampsia eclampsia. Am J Obstet Gynecol. 1990;163(5Pt 1):1714-5.

26. Witlin AG, Sibai BM. Magnesium Sulphate therapy in preeclampsia and eclampsia. Obstet Gynecol. 1998;92(5):883-9.

27. Azria E, Tsat saris Y, Goffinet F, Kayem G, Mignon A, Cabrol D. Magnesium Sulphate in obstetrics: current data. J Gynecol Obstet Biol Reprod(Paris). 2004;33(6Pt 1):510-17.

28. Altman D, Carroli G, Duley L, Farrell B, Moodley J, Neilson J, et al. Do women with pre-eclampsia, and their babies, benefit from magnesium sulphate? The Magpie Trial: a randomised placebo-controlled trial. Lancet. 2002;359:1877.
29. Sibai BM. Magnesium sulfate prophylaxis in preeclampsia: Lessons learned from recent trials. Am J Obstet Gynecol. 2004;190(6):1520.

30. Abate M, Lakew Z. Eclampsia. A 5 years retrospective review of 216 cases managed in two teaching hospitals in Addis Adaba. Ethiop Med J. 2006;44(1):27-31.

31. Onuh SO, Aisian AO. Maternal and fetal outcome in eclamptic patients in Benin city, Nigeria. J Obstet Gynaecol. 2004;24(7):765-8.

32. Tukur J, Umar NI, Khan N, Musa D. Comparison of emergency caesarean section to misoprostol induction for the delivery of antepartum eclamptic patients: a pilot study. Niger J Med. 2007;16(4):364.

33. Seal SL, Ghosh D, Kamilya G, Mukherji J, Hazra A, Garain P. Does route of delivery affect maternal and perinatal outcome in women with eclampsia? A randomized controlled pilot study. Am J Obstet Gynecol. 2012;206(6):484.e1.

34. Duley L, Gulmezoglu AM. Magnesium sulphate versus lytic cocktail for eclampsia. Cochrane Database Syst Rev. 2001;CD002960.

35. Duley L, Henderson-Smart D. Magnesium sulphate versus diazepam for eclampsia. Cochrane Database Syst Rev. 2003;CD000127.

36. Duley L, Henderson-Smart D. Magnesium sulphate versus phenytoin for eclampsia. Cochrane Database Syst Rev. 2003;CD000128.

Cite this article as: Gandhi G, Chandnani K. A prospective study of the incidence and outcomes of eclampsia in a tertiary care hospital and teaching institute in India. Int J Reprod Contracept Obstet Gynecol 2019;8:2766-72. 